\title{
Remission of acute monocytic leukemia, secondary to treatment with epipodophyllotoxins, in a patient with $\mathrm{t}(8 ; 16)(\mathrm{p} 11 ; \mathrm{p} 13)$ and MYST3-CREBBP fusion
}

The balanced $\mathrm{t}(8 ; 16)(\mathrm{p} 11 ; \mathrm{p} 13)$ is found in less than $1 \%$ of acute myeloid leukemia (AML) patients, usually associated with specific clinicopathologic findings such as blast differentiation (French-American-British [FAB] subtypes M4/ M5), absence of previous MDS in young individuals of both sexes, presence of erythrophagocytosis, and poor response to chemotherapy, with a poor prognosis and mean survival less than 1 year [1]. This translocation results in the fusion of the CREBBP gene (alias $C B P$ ) located at $16 \mathrm{p} 13.3$ with the MYST3 gene (previously known as RUNXBP2; alias $M O Z)$ located at $8 \mathrm{p} 11.2$ [2,3], which have been suggested to be targets for topoisomerase II inhibitors and anthracyclines, respectively. There are, however, very few reported cases of patients with both this translocation and AML secondary to treatment with these drugs [3-7].

A 24-year-old man was diagnosed with a mediastinal seminoma on May 2001. He received four cycles of chemotherapy with cisplatin, etoposide, and dexamethasone; the remaining mediastinal mass was surgically removed. He was diagnosed with acute monocytic leukemia (FAB subtype M5b) in November 2002, presumably secondary to treatment with epipodophyllotoxins. Bone marrow aspirate revealed infiltration with $92 \%$ large blasts weakly positive for myeloperoxidase staining and negative for chloroacetate esterase staining. Immunophenotyping with forward scatter-side scatter (FS/SS) gating identified two separate populations of blasts, both of which were $\mathrm{CD} 33^{+}, \mathrm{CD} 15^{+}, \mathrm{CD} 4^{-}, \mathrm{CD} 56^{-}$, and $\mathrm{CD} 34^{-}$. Weak erythrophagocytosis was observed. Cytogenetic analysis revealed the karyotype 46,XY,t( $8 ; 16)$ (p11;p13) in $7 \%$ of the metaphases analyzed (Fig. 1A). Remission was achieved after treatment according to the PETHEMA protocol, and all metaphases were normal by December 2002. The patient received a bone marrow transplant and was, at writing, in molecular and cytogenetic remission.

Fluorescence in situ hybridization (FISH) studies with bacterial artificial chromosomes (BACs) RPCI-11 461A8 and RPCI-11 95J11 were consistent with a rearrangement of $C B P$ (Fig. 1B). Reverse transcriptase-polymerase chain reaction (RT-PCR) [3] confirmed the presence of the in-frame 1128-bp MOZ-CBP fusion transcript (only type I transcript;
Fig. 1C) and also the presence of the $C B P-M O Z$ transcript (data not shown). The sequence of the chimeric transcripts (Fig. 1D) revealed breakpoints similar to those described previously, fusing exon 16 from $\mathrm{MOZ}$ to exon 3 from $C B P$.

In summary, we describe a $\mathrm{t}(8 ; 16)(\mathrm{p} 11 ; \mathrm{p} 13)$ with $\mathrm{MOZ}$ $C B P$ fusion in a patient with AML 5b secondary to treatment

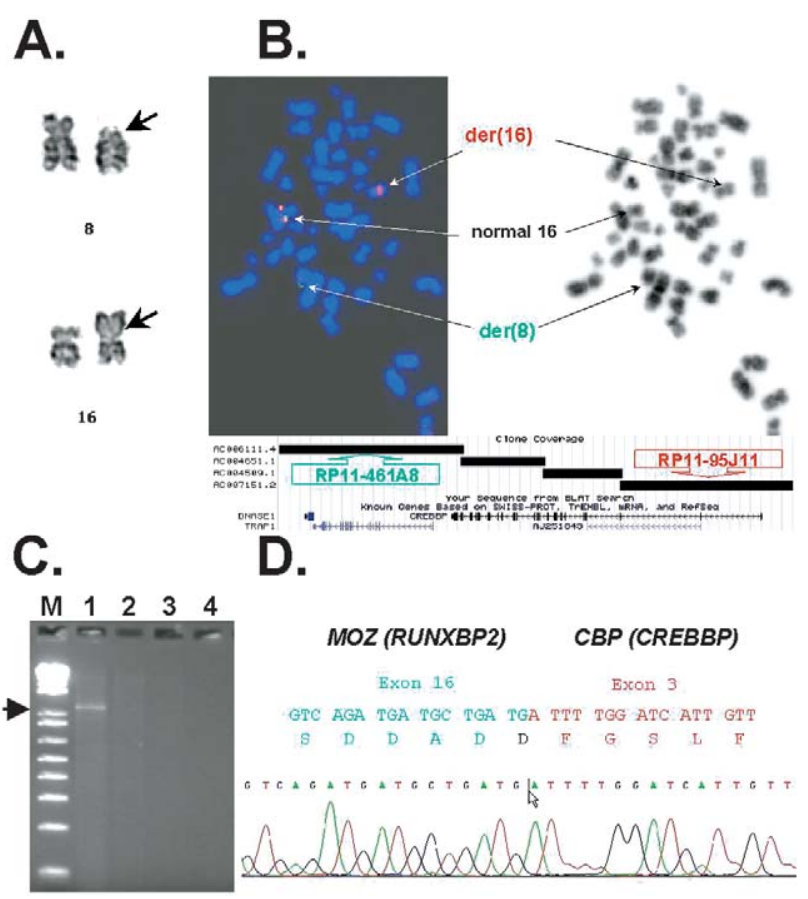

Fig. 1. (A) Partial G-banding karyotype showing the $\mathrm{t}(8 ; 16)(\mathrm{p} 11 ; \mathrm{p} 13)$; arrows indicate breakpoints. (B) FISH analysis with BACs RPCI-11 461A8 and RPCI-11 95J11. A green signal in $\operatorname{der}(8)$ and a red signal in $\operatorname{der}(16)$ are indicative of $C B P$ splitting. A screen-shot from the UCSC Genome Browser (July 2003 version, http://genome.ucsc.edu) is shown below, displaying the relative position of the BAC clones used in FISH. (C) RT-PCR amplification of the chimeric type I MOZ-CBP transcript (1128 bp). Lane M: 1-Kb ladder Plus molecular weight marker (Invitrogen-Life Technologies, Paisley, UK); lane 1: patient sample at the moment of diagnosis; lane 2: patient sample after therapy; lane 3: sample from a healthy subject; lane 4: negative control. $(D)$ Sequence of the RT-PCR product obtained in $(A)$ showing an in-frame fusion between $M O Z$ exon 16 and $C B P$ exon 3. 
with epipodophyllotoxins. The presence of this translocation is usually associated with strong erythrophagocytosis and CD34 ${ }^{-} / \mathrm{CD}^{2} 6^{+}$blasts [7]. This patient, however, displayed weak erythrophagocytosis and $\mathrm{CD}^{-} 6^{-}$blasts, with a low percentage of cells showing the translocation. Moreover, RT-PCR detected only type-I (in-frame) fusion transcripts, but no type II (out-of-frame) transcripts. All these peculiarities could account for the good prognosis of this patient, who responded well to conventional therapy and is in cytogenetic and molecular remission after bone marrow transplantation, in contrast to other published cases.

\section{Acknowledgments}

This study was supported by grant no. 05/903 from the Department of Health of the Government of Navarra, Spain, and by a grant from the PIUNA Projects from the University of Navarra, Spain.

José L.Vizmanos

María J.Larráyoz Iria Vázquez

María D. Odero

Department of Genetics, School of Sciences

Universidad de Navarra Pamplona

C/Irunlarrea 1

ES-31008 Pamplona, Navarra, Spain

Roberto Hernández

Hematology Service

Txagorritxu Hospital

Servicio Vasco de Salud-Osakidetza

Vitoria, Spain

Idoya Lahortiga

Francisco J. Novo

Department of Genetics, School of Sciences

Universidad de Navarra Pamplona

Pamplona, Navarra, Spain

\author{
María T. Ardanaz \\ Hematology Service, Txagorritxu Hospital \\ Servicio Vasco de Salud-Osakidetza \\ Vitoria, Spain \\ María J. Calasanz \\ Department of Genetics, School of Sciences \\ Universidad de Navarra Pamplona \\ Pamplona, Navarra, Spain
}

\section{References}

[1] Pérot C, Huret JL. t(8;16)(p11;p13). In: Atlas of Genetics and Cytogenetics in Oncology and Haematology [Internet]. Updated December 1998. Available at http://www.infobiogen.fr/services/chromcancer/ Anomalies/t0816.html.

[2] Borrow J, Stanton VPJ, Andresen JM, Becher R, Behm FG, Chaganti RSK, Civin CI, Disteche C, Dube I, Frischauf AM, Horsman D, Mitelman F, Volinia S, Watmore AE, Housman DE. The translocation $\mathrm{t}(8 ; 16)(\mathrm{p} 11 ; \mathrm{p} 13)$ of acute myeloid leukaemia fuses a putative acetyltransferase to the CREB-binding protein. Nat Genet 1996;14:33-41.

[3] Panagopoulos I, Isaksson M, Lindvall C, Björkholm M, Ahlgren T, Fioretos T, Heim S, Mitelman F, Johansson B. RT-PCR analysis of the MOZ-CBP and CBP-MOZ chimeric transcripts in acute myeloid leukemias with $\mathrm{t}(8 ; 16)(\mathrm{p} 11 ; \mathrm{p} 13)$. Genes Chromosomes Cancer 2000;28: $415-24$.

[4] Schneider DT, Hilgenfeld E, Schwabe D, Behnisch W, Zoubek A, Wessalowski R, Gobel U. Acute myelogenous leukemia after treatment for malignant germ cell tumors in children. J Clin Oncol 1999;17:3226-33.

[5] Bernasconi P, Orlandi E, Cavigliano P, Calatroni S, Boni M, Astori C, Pagnucco G, Giglio S, Caresana M, Lazzarino M, Bernasconi C. Translocation $(8 ; 16)$ in a patient with acute myelomonocytic leukemia, occurring after treatment with fludarabine for a low-grade nonHodgkin's lymphoma. Haematologica 2000;85:1087-91.

[6] Camós M, Colomer D, Esteve J, Rozman M, Villamor N, Plancarte F, Campo E, Montserrat E. Secondary acute myeloid leukemia with $M O Z / C B P$ fusion gene following treatment with topoisomerase-II inhibitors. Presented at 2nd International Symposium on Secondary Leukemia and Leukemogenesis. Rome, October 2002.

[7] Villamor N, Rozman M, Camós M, Plancarte F, Colomer D, Domingo A, Navarro T, Solé F, Carrió A, Aventin A, Esteve J, Aymerich M, Aguilar JL, Montserrat E. Acute myeloid leukemia with $\mathrm{t}(8 ; 16)$ displays characteristic morphologic and immunophenotypic features. Abstract 4552. American Society of Hematology 44th Annual Meeting. Philadelphia, Pennsylvania, December 2002. 